\title{
ENTRE EL REALISMO Y LA ABSTRACCIÓN: UNA EVALUACIÓN METODOLÓGICA DE LA MACROECONOMÍA
}

\author{
Por: Gonzalo Cómbita Mora ${ }^{1}$
}

\section{RESUMEN}

El presente artículo muestra cómo la macroeconomía moderna está constituida por una gama de modos de pensar que enriquecen el debate y permiten el avance de la ciencia. No obstante, esta pluralidad metodológica ha sido anulada por el dominio del enfoque mainstream que ha jalonado el progreso científico en una dirección equivocada buscando una mayor consistencia lógica y matemática, llevando la capacidad de explicación de los modelos a su más mínima expresión. El artículo muestra que esta incapacidad de explicación se ha manifestado en una creciente insatisfacción sobre la utilidad de la teoría macroeconómica. Además, presenta la diversidad de pensamiento en macroeconomía y su avance como ciencia comparando el enfoque maintream y post keynesiano, encontrando serias diferencias metodológicas que se manifiestan en el grado de retroalimentación de la teoría con la realidad, lo que afecta su relevancia práctica. Se concluye que el dominio del mainstream ha anulado el avance de la macroeconomía pues ha invalidado los debates presentando como científico un solo camino, lo que ha derivado en la omisión de diferentes enfoques que pueden cuestionar y ampliar las preguntas de investigación, la variables relevantes y su relación de causalidad, así como el uso de las matemáticas.

Palabras clave: macroeconomía, metodología, heterodoxia.

Clasificación JEL: B22, B41, B50.

1. Magister en Ciencias Económicas, Universidad Nacional de Colombia.- Docente investigador tiempo completo, Programa de Economía Universidad de la Salle, Bogotá.- E-mail: gcombita@unisalle. edu.co,goncomo@gmail.com 


\title{
BETWEEN REALISM AND ABSTRACTION: A METHODOLOGICAL ASSESSMENT OF MACROECONOMICS
}

\author{
By: Gonzalo Cómbita Mora
}

\begin{abstract}
This paper states how modern macroeconomics is made up by a wide range of modes of thought which fortify the debate and allow the progress of science. However, this methodological plurality has been annulled by the dominance of the mainstream approach that has driven the scientific progress in the wrong way, seeking more logical and mathematical consistency, which leaves the explanatory power of the model to its minimum expression. This paper shows that this inability has arisen in a growing dissatisfaction on the usefulness of macroeconomic theory. Moreover, diversity of thought in macroeconomics is shown, as well as its advance as science comparing the mainstream approach with post Keynesian one, finding serious methodological differences which are become evident in the feedback degree between theory and reality what affects its practical relevance. As a conclusion we may say that the dominance of mainstream has prevented macroeconomics from making progress as it has invalidated the debates showing a single scientific path, what has led to the omission of different approaches that might challenge and expand the research questions, the relevant variables and its causality relations, the use of mathematics.
\end{abstract}

Key words: macroeconomics, methodology, heterodox.

JEL classification: B22, B41, B50. 


\section{Introducción}

Milton Friedman, es un reconocido profesor de la Universidad de Chicago que representa los más altos estándares de cientificidad que ha alcanzado la economía como ciencia, lo cual se refleja en su Premio Nobel de 1976, y en la consolidación de su libro Essays in Positive Economics de 1953, que junto al artículo de L. Robbins de 1932, se pueden considerar dos obras que muestran cómo se ha construido, epistemológicamente, la economía moderna. Los estándares seguidos por estos autores obedecen a lo que Dow (1998) reconoce como una de las formas de construir conocimiento en las ciencias, el modo Euclidiano/Cartesiano, que privilegia el razonamiento lógico sobre la comprobación empírica, de allí que algunas teorías económicas sean construidas con alto nivel de abstracción, que no se juzga como erróneo, pues las teorías muestran su importancia cuando deducen leyes de comportamiento que luego son útiles para predecir el comportamiento de las variables analizadas.

El artículo busca explicar cómo la macroeconomía, un sub-campo de la economía, ha seguido la tradición del enfoque Euclidiano a través del modo de pensar neoclásico (ortodoxos/mainstream), que se condensa en las escuelas; monetarista, nueva macroeconomía clásica (NMC), ciclos reales de los negocios (RBC) e inclusive la nueva macroeconomía keynesiana (NMK). Estas escuelas han jalonado el progreso científico de la macroeconomía en una dirección equivocada, buscando una mayor consistencia lógica y matemática que constituye un grave problema de construcción metodológica que deriva en una absoluta irrelevancia del conocimiento generado en esta área de la economía, llevando la capacidad de explicación de los modelos a su más mínima expresión.

También se mostrará que la macroeconomía goza de una pluralidad metodológica y que el mainstream no es el único camino epistemológico en esta área, por ello, se buscará presentar el modo de pensar post keynesiano (heterodoxo) que posee una base metodológica diferente al mainstream, la babilónica, que a través del realismo crítico busca explicar más que predecir, de este modo la teoría siempre estará subordinada a la realidad desde sus etapas iniciales de creación hasta la puesta en práctica con la política económica. El criterio de efectividad de este enfoque es su relevancia práctica para alterar la realidad y no su capacidad de predicción.

El presente artículo considera importante mostrar como la macroeconomía moderna está constituida por una gama de modos de pensar tales como el mainstream, el post keynesianismo, la economía austriaca y el marxismo que enriquecen el debate y permiten el avance de la ciencia. No obstante, esta pluralidad metodológica ha sido anulada por el dominio del enfoque mainstream generando consecuencias negativas en la investigación macroeconómica, pues al invalidar el debate se ha perdido la posibilidad de cuestionar y ampliar las preguntas de investigación, encontrar diferentes variables relevantes y su relación de causalidad, así como aplicaciones de la matemáticas que no necesariamente validen las cientificidad de las teorías, sino que funcionen como herramientas de representación más neutras epistemológicamente en los modelos teóricos. Además, la importancia del artículo radica en develar a las académicos, sobre todo aquellos en etapas de formación 
iniciales o los que buscan alternativas metodológicas ${ }^{2}$, el porqué del nivel de abstracción y matematización de la macroeconomía junto a la posibilidad de apreciar un método alterno al mainstream como lo es el post keynesiano.

La naturaleza de la investigación propuesta en este artículo es exploratoria dado que en él se pretende visibilizar la pluralidad metodológica de la que goza la teoría macroeconómica, resaltando el sesgo que se tiene por una de estas metodologías. Lo anterior busca servir como base para futuras investigaciones o información indispensable en los cursos de formación en el área, al recoger los principales debates alrededor del tema junto con una hipótesis inicial sobre el estado de la construcción teórica en macroeconomía, para lograr el cometido se propone inicialmente resaltar la fragilidad y la responsabilidad de las teorías macroeconómicas neoclásicas modernas sobre los pobres resultados macroeconómicos de algunos países, luego se revisa la evolución de la macroeconomía a la luz de la filosofía de la ciencia, a continuación se presenta a los modelos ortodoxos y post keynesianos como representantes de la pluralidad metodológica en macroeconomía entre la postura Euclidiana y babilónica, y al final se compara la postura neoclásica con la post keynesiana alrededor de la microfundamentación, el equilibrio, el rol del dinero y las expectativas.

\section{La teoría macroeconómica: ¿parcialmente en lo cierto o equivocados con exactitud?}

La Teoría General describe muy bien la preocupación por el excesivo grado de idealización de los modelos macroeconómicos ortodoxos buscando una consistencia lógica y matemática, pero que dan la espalda a la realidad que pretenden explicar por lo que sus prescripciones suelen empeorar las condiciones macroeconómicas reales. Al respecto Keynes mencionó: "Las características de [...] la teoría clásica no son las de la sociedad económica en la que vivimos, razón por la que sus enseñanzas engañan y son desastrosas si intentamos aplicarlas a los hechos reales" (Keynes, 1936, p. 37).

En ese sentido, Bouchaud (2008) publicó un artículo en la revista científica Nature acerca de cómo la economía fue incapaz de predecir la crisis financiera de 2008. Bouchaud muestra que el problema se encuentra en la construcción metodológica de los modelos económicos que descansan sobre axiomas no sujetos a prueba empírica, lo que deriva en teorías abstractas incapaces de predecir el comportamiento de los mercados, este autor recomienda a los economistas seguir el proceso epistemológico de falsación Popperiano empleado en la física, donde

2. En noviembre de 2011 estudiantes del curso de introducción a la economía en Harvard redactaron una carta levantando una voz de inconformismo con los contenidos impartidos por el reconocido profesor Gregory Mankiw. Los estudiantes manifestaron su descontento por la falta de pluralidad en la explicación de los temas de la materia, por lo que demandaban explicaciones desde otras posturas como la keynesiana o la marxista. Esta protesta, que se suma a la hecha en Francia a mediados del año 2000, reclama de la economía mayor relevancia práctica con los problemas y hechos contemporáneos actuales y menos abstracción. La carta contra el profesor Mankiw puede ser consultada en http:/hpronline.or/harvard/an-open-letter-to-greg-mankiw/, y para disponer de información del grupo francés se puede consultar en http://www.paecon.net/HistoryPAE.htm. 
los modelos teóricos son puestos a prueba continuamente desechando aquellos que señalen poca relevancia empírica aun cuando tengan consistencia y elegancia lógica y matemática.

En el mismo sentido, se encuentra el trabajo de Reinert (2012) quien muestra cómo la puesta en práctica desde los años 70’s de la teoría neoclásica ha empeorado el desempeño macroeconómico a corto y largo plazo de variables como el producto per cápita y el empleo de los países en desarrollo inicialmente, y recientemente a los países del primer mundo, mediante programas de ajuste estructural, liberalización del comercio y de capitales. Esto se puede apreciar en la desaceleración del crecimiento del PIB per cápita en casi todas las regiones del mundo excepto en Asia. Según el autor, esto se debe a la victoria del modelo ricardiano de comercio que ignora los rendimientos crecientes, las diferencias de especialización en sectores primarios con baja creación de valor agregado en contra de otros con mejor desempeño y calidad de arrastre.

Reinert menciona que, metodológicamente, la macroeconomía ortodoxa ha olvidado "los principales factores que no pueden ser formalizados y matematizados, factores que determinan las diferencias cualitativas entre actividades económicas, y factores que desencadenaron la crisis financiera de 2008, lo cuales son dejados fuera del edificio teórico de la economía” (Reinert, 2012, p. 8).

A lo anterior se suma el trabajo de Mitchell y Muysken (2008) que muestran cómo, para el caso de los países de la Organización para la Cooperación y el Desarrollo Económico (siglas en inglés OECD), el abandono de estrategias de impulso y estabilización de variables reales privilegiando la estabilidad nominal, derivó en una creciente y acumulativa subutilización de recursos productivos con su consiguiente impacto en el crecimiento económico. De hecho, dejan en evidencia que el abultado déficit del sector público no se debe a un mal manejo de las finanzas públicas, sino a las consecuencias de abandonar las políticas de pleno empleo que han derivado en una acumulación progresiva de población en edad de trabajar que no consigue emplearse y recurre al Estado, lo cual contradice las tesis convencionales acerca de que los subsidios al desempleo alientan a los individuos a demandar más ocio, es decir, a aumentar las filas del desempleo voluntario. En otras palabras, no se le ve al desempleo como un fenómeno macroeconómico sino como causa de decisiones individuales voluntarias, lo que oculta la incapacidad de creación de puestos de trabajo de las economías.

A su vez, Mitchell y Muysken (2008) explican que la publicación del Job Study: Facts, analysis and strategies en 1994, marcó la realización de una serie de recomendaciones basadas en las teorías de mercado de trabajo de los Nuevos Keynesianos, donde este mercado es mirado de forma aislada al resto de mercados en la economía y sujeto a imperfecciones. Los autores llaman a esta estrategia como política de empleabilidad donde las instituciones sociales de protección no juegan un rol de creación de puestos sino de acompañamiento al individuo en su búsqueda de empleo en el mercado laboral. 
Otro aspecto relevante del trabajo de Mitchell y Muysken (2008) es la construcción de dos indicadores de evaluación de política macroeconómica denominados indicadores de miseria macroeconómica IM, y miseria aumentada IMA, respectivamente. El IM es la suma de la inflación y el desempleo para el grupo de países seleccionado, con él se busca mostrar cómo a pesar de la significativa caída de las tasas de inflación a un digito, en promedio cercanas al 2\% para 2005, el IM se mantiene e incluso crece de 1985 a 2005 para algunos de los países, mostrando que las ganancias en control de la inflación han sido más que compensadas por la subida del desempleo, pero el IMA es todavía más contundente, pues al ser la suma de la inflación, el desempleo y el subempleo por horas muestra el deterioro del empleo en cantidad y calidad. Al respecto, puede observarse el aumento significativo de los indicadores al pasar del IM al IMA, diferencia que se hace evidente en el 2005. Estos resultados, según los autores, muestran la debilidad de las políticas de auto empleabilidad y oferta.

Schettkat (2010) presenta un trabajo sobre el impacto macroeconómico que ha traído en España la aplicación de la Teoría del desempleo natural de la NMC de Lucas. Para Schettkat esta teoría tiene sólidas bases microeconómicas pero pocos datos empíricos que la respalden, para él la posición de la NMC sostiene que los mercados son eficientes, la política monetaria tiene efectos neutros y la política de gasto público deficitario es ineficaz (basado en el principio de equivalencia Ricardiana) para alterar la demanda y el producto.

El punto esencial del trabajo de Schettkat es, que la teoría de la tasa natural al considerar que el desempleo es neutro a la política monetaria recomienda un manejo contractivo de este instrumento, lo que en Europa ha derivado en que los Bancos Centrales manejen de forma asimétrica su política en los ciclos, pues en las recesiones tratan de estimular la economía pero cuando ésta muestra algún síntoma de recuperación se presume que se incuba un potencial inflacionario, lo que deriva en una política monetaria restrictiva que detiene la economía prematuramente evitando que cree puestos de trabajo, lo que ha terminado en 30 años de acumulaciones persistentes de desempleo hasta llegar a las posiciones actuales.

También Schettkat (2010) encuentra que la teoría de la NMC, al fundarse sobre el libre funcionamiento de los mercados, ha permitido la desregulación de los capitales financieros, el empeoramiento de las condiciones de empleo al imponer reformas de flexibilización que buscan acercar el mercado de trabajo a su versión ideal de libro de texto y la concentración del ingreso con políticas tributarias regresivas. Finalmente el autor, menciona que la mezcla de todo lo anterior ha creado un escenario proclive para la especulación y la estrangulación de la actividad económica real.

Para Morata (2011), Mario Bunge resume muy bien las posiciones de insatisfacción expresada en los trabajos antes comentados, pues como partidario del realismo crítico considera a la economía (microeconomía) una pseudociencia dado que sus postulados son abiertamente irreales, difusos y de difícil comprobación. Bunge también concuerda en que la economía oculta su incompetencia detrás de una fachada matemática que intimida al analfabeto en esos temas. 


\section{Formas de pensar en macroeconomía: una reflexión desde la filosofía de la ciencia}

Como se mencionó, la creciente insatisfacción sobre la teoría macroeconómica ha conducido a varios autores a realizar una revisión en la forma en que es construida la misma teoría, es decir, un replanteamiento de la forma de pensar ${ }^{3}$ y generar conocimiento hacia los problemas que se abordan en este documento. Este debate pertenece a una reflexión filosófico-metodológica en economía que, como menciona Gonzalez (2001), se puede abordar desde una visión amplia y una específica. La primera busca conectar la ciencia económica con las orientaciones generales de la metodología como la verificacionista, la falsacionista y la estructuralista ${ }^{4}$. La segunda trata de acercar estas orientaciones de la metodología en economía a componentes específicos de la misma como la microeconomía y la macroeconomía.

Este trabajo se adhiere a la segunda visión, por lo que inicialmente se mira cómo puede ser percibida, a la luz de la filosofía de la ciencia, la evolución del pensamiento macroeconómico a lo largo del siglo XX desde su origen en el modelo clásico hasta sus desarrollos más recientes, para luego mostrar cómo la reflexión metodológica de la macroeconomía pertenece a un marco de análisis dicotómico más amplio entre el modo de pensar Cartesiano/Euclidiano y el Babilónico.

Para realizar la evaluación de la teoría macroeconómica desde la filosofía de la ciencia se seguirán los trabajos de Popper, Kuhn, Lakatos, Laudan y Feyeraben. Según Snowdon, Vane y Winarczyk (1994) Popper presenta su tesis fundamental de falsación, la cual menciona que si no se puede verificar o confirmar las hipótesis o premisas de una teoría, por lo menos podríamos comprobar que no es cierta, en sus términos falsearla. Sin embargo, en economía no se suele recurrir a la falsación, y por el contrario, surgen continuamente nuevas ideas dentro de modelos previos ${ }^{5}$ que perfeccionan su grado de complejidad, consistencia y lógica matemática, sin tener en cuenta su relevancia con la realidad, lo que deriva en serias dificultades empíricas. Sin embargo, este inconveniente no es generalizado pues las ideas de Popper tienen acogida en el post keynesianismo a través del realismo crítico como método alterno en macroeconomía, lo cual se discutirá más adelante.

Otro autor reconocido de la filosofía de la ciencia es Kuhn, que de acuerdo con Blaug (1980), considera que la ciencia tiene periodos de continuidad y progreso liderados por episodios de crisis o anomalías. El concepto más reconocido de Kuhn es el paradigma -forma de ver el mundo o la estructura- que involucra una matriz disciplinar y otra ejemplar, la primera se refiere al conjunto de creencias, valores,

3. La "forma de pensar" es un concepto que introdujo Dow (1998) mostrando que existen diferentes maneras de abordar los problemas de la macroeconomía que no comparten estructuras metodológicas y teóricas similares, por lo que el debate doctrinal en macroeconomía debería reconocer tales diferencias.

4. La propuesta estructuralista recoge las visiones de Kuhn, Lakatos y Laudan.

5. El caso común de nuevas ideas se evidencia el continuo batallar de los tradicionales modelos Clásico y Keynesiano, que se ha ido renovando en escuelas más nuevas como los Nuevos Keynesianos, Post Keynesianos o Nueva Macroeconomía Clásica (NMC), sin que estas versiones nuevas dejen invalidas las hipótesis de sus predecesores. Aun cuando se innova sobre una misma escuela como puede ser el caso de los monetaristas marca I y luego la NMC, también conocida como Monetarista marca II las tesis de la segunda no invalidan las de la primera. 
técnicas compartidas por los miembros de una comunidad científica, y la segunda el problema o enigma a solucionar.

Según Kuhn la madurez de la disciplina se alcanza cuando se hace una transición a un consenso, es decir, el desarrollo de la ciencia se da como una secuencia de movimientos hacia situaciones de monopolio de un paradigma mediante revoluciones. A diferencia de Popper donde la crítica es bienvenida, Kuhn menciona que los paradigmas buscan defenderse de los ataques, por ello las revoluciones son vistas como ocasionales y caracterizadas por periodos de intensa competencia de paradigmas (Snowdon, Vane \& Winarczyk, 1994).

La idea del avance de la ciencia de Kuhn aplicada en macroeconomía, muestra cómo la teoría neoclásica (mainstream) ejerce un monopolio casi absoluto en la enseñanza de esta área desde la contra revolución keynesiana propuesta por los monetaristas como Milton Friedman, y luego afianzada por los nuevos macroeconomistas clásicos como Robert Lucas y Thomas Sargent. De hecho, el dominio de las ideas de estos autores ha sido tal que al referirse a la macroeconomía, o incluso a la economía en general, se asume que la macroeconomía neoclásica es equivalente a la macroeconomía como tal (Denis, 2013), omitiendo otras posturas como el marxismo, post keynesianismo, institucionalismo etc. Adicionalmente, se ha visto como varios de los ataques recibidos a la superestructura neoclásica han sido sorteados incorporando estos desafíos dentro de sus explicaciones ${ }^{6}$.

No obstante, contrario a lo mencionado, la tesis de Kuhn no funciona en macroeconomía pues no existe un paradigma dominante, y como se verá más adelante, subsisten modelos con estructuras metodológicas distintas con fuertes discrepancias respecto del rol de la incertidumbre, el dinero, el equilibrio y la microfundamentación. Una evaluación de la macroeconomía desde Kuhn diría que estamos en un periodo de transición de caída del keynesianismo o simplemente nunca ha sido una ciencia madura, pues han coexistido diferentes paradigmas antes y después de Keynes (Snowdon, Vane \& Winarczyk, 1994).

Por otra parte, Bernal (2000), Blaug (1980) y Snowdon, Vane \& Winarczyk (1994) consideran que Lakatos trata de rescatar a Kuhn diciendo que los programas de investigación científica se componen de lo que denomina hard core y un cinturón protector de hipótesis auxiliares. El hard core es axiomático y por ende no es verificado empíricamente, pero las teorías construidas alrededor de él si pueden serlo, por lo que se le pone a prueba de manera indirecta ${ }^{7}$. Según Lakatos los programas de investigación pueden ser progresivos y degenerativos, los progresivos mues-

6. Ejemplo de ello es el modelo de síntesis neoclásica que tomó prestado de Keynes los únicos elementos compatibles con su método (Dow, 1998). Otro ejemplo es la incorporación de la competencia imperfecta en los modelos neo keynesianos, y un ejemplo adicional son los rendimientos crecientes de Young en 1928 que se contemplaron dentro del modelos neoclásico en los modelos de crecimiento endógeno recientes.

7. Un ejemplo del Hard core en economía se traduce en supuestos como el ajuste automático, racionalidad de los agentes, entre otros. 
tran superioridad teórica y empírica, y su triunfo marca la generación de nuevo conocimiento $^{8}$. La tesis de este autor tuvo aceptación en la macroeconomía por concebir la convivencia de programas en competencia, pero el privilegio que dio al concepto empírico por encima de lo analítico dejo sin aire a la muy abstracta macroeconomía moderna.

La idea de resolución de problemas de Laudan es otra buena aproximación metodológica de la macroeconomía. Esta posición da valor a una teoría o tradición de investigación de acuerdo a la cantidad de problemas que pueda resolver respecto de sus competidoras (Snowdon, Vane \& Winarczyk, 1994). Desde esta perspectiva pueden haber múltiples teorías dentro de un programa de investigación, por eso esta aproximación se acerca a la macroeconomía pues menciona que las tradiciones de investigación y sus teorías pueden subsistir en un ambiente de continua competencia y evaluación, y su forma de comunicarse se da a través de las mismas preocupaciones como el desempleo, la inflación, etc.

Desde una perspectiva similar a Laudan, Feyerabend promueve la tolerancia hacia otras formas de pensar expresadas en diferentes paradigmas con su propio lenguaje, técnica, metafísica y evaluación propia de su teoría (Dow, 1998). Se trata de una aproximación pluralista que no se atreve a establecer juicios universales de evaluación sobre la cientificidad de un método en particular.

Las posiciones de Laudan y Feyeraben parecen estar más acordes con la creación de conocimiento en macroeconomía que se materializa en modelos teóricos con diferentes estructuras metodológicas. Lo anterior se evidencia con mayor nitidez a partir de la variedad de escuelas macroeconómicas desarrolladas a lo largo del siglo XX.

La tabla 1 muestra la diversidad antes mencionada desde la postura de Snowdon y Vane (2005) y Dow (1998). La primera clasificación muestra cómo el desafío empírico y teórico durante el siglo XX (por ejemplo el shock petrolero de los 70's o la microfundamentación) promovió el surgimiento de escuelas de pensamiento o renovó las respuestas de otras como el caso del post keynesianismo y la escuela austriaca. No obstante, Dow (1998) propone una clasificación basada en la diferencia metodológica donde se reconoce cuatro posiciones con diferentes visiones del mundo ${ }^{9}$, las cuales abarcan varias escuelas en su interior, que comparten rasgos comunes en aspectos como la noción de equilibrio, la incorporación de las expectativas, la incorporación del dinero, la microfundamentación y el vínculo entre teoría y política.

8. Según Snowdon, Vane \& Winarczyk (1994), un ejemplo fue lo que mostró el monetarismo en los 70's con su superioridad empírica sobre el IS-LM que era degenerado teóricamente.

9. Para Scarano (2001) la variedad de escuelas de pensamiento en macroeconomía permite un elevado grado de competencia, que contrario a los que piensan que le quita contundencia, por el contrario, refuerza el proceso de renovación y ampliación de conocimiento en el tema. 
Tabla 1

CLASIFICACIÓN DE LAS ESCUELAS MACROECONÓMICAS

\begin{tabular}{|c|c|}
\hline Clasificación Snowdon y Vane (2005) & Clasificación Dow (1998) \\
\hline Clásico original & \multirow{5}{*}{ Mainstream } \\
\hline Monetarismo marca I & \\
\hline Nueva Macroeconomía Clásica (NMC) & \\
\hline Ciclos Reales de los Negocios (RBC) & \\
\hline Nueva Macroeconomía Keynesiana (NMK) ${ }^{1}$ & \\
\hline Keynesiano Original & \multirow{2}{*}{ Post Keynesiana } \\
\hline Post Keynesiana (PK) & \\
\hline \multirow[t]{2}{*}{ Escuela Austriaca } & Escuela Austriaca \\
\hline & Marxismo $^{2}$ \\
\hline
\end{tabular}

Fuente: Elaboración propia.

Dow (1998) menciona que el debate alrededor de la metodología en macroeconomía ha quedado dominado por la postura mainstream, también llamada neoclásicas u ortodoxa, pues a partir de su lenguaje y propia visión del mundo demarca un límite entre el conocimiento que se considera científico y el que no lo sería, para Dow (1998) este problema se puede reflejar en una vieja pugna entre dos formas de pensar distintas a la hora de crear conocimiento en general; este marco amplio de discusión muestra cómo las teorías y argumentos son construidos y presentados bajo un esquema dicotómico que puede abarcar la denominada perspectiva Euclidiana/Cartesiana y el enfoque Babilónico, como se mencionó con anterioridad.

Esta clasificación ha sido desarrollada por Dow (1998) quien muestra cómo la perspectiva Euclidiana/Cartesiana tiene su origen en la filosofía griega donde la mente/alma podían ser cultivadas como virtud una vez se han separado de la materia. Es por esto que esta perspectiva se caracteriza por una construcción axiomática, que deriva en teoremas abstractos luego de un arduo de proceso de indagación lógica introspectiva tratando de extraer leyes generales alrededor del problema en estudio sin ningún anclaje a la realidad. Además, su construcción se considera un sistema cerrado pues se conocen muy bien sus límites, variables incluidas junto con las relaciones de causalidad entre ellas. Fuera de su sistema cualquier perspectiva es considerada conocimiento no científico, una mera herejía ${ }^{\mathbf{1 2}}$.

10. Caraballo, Galindo y Usabiaga (2000) muestran de manera clara como la NMK tiene la misma estructura metodológica anclada al modelo de equilibrio general que tiene el modelo de NMC.

11. El marxismo puede ser incorporado al Post Keynesianismo a través de la obra de Michael Kalecki tal y como lo muestra su biógrafo en Lopéz (2008), López y Assous (2010).

12. La Post Keynesiana Joan Robinson en 1980 publicó un libro que denominó Herejías Económicas tratando de mostrar la pluralidad de conocimiento respecto del pensamiento ortodoxo anclado en el ajuste automático y laisser faire. 
Por el contrario, la perspectiva babilónica no busca un razonamiento lógicoabstracto sino la solución práctica de los problemas planteados por medio de la intervención directa, en ese sentido sus planteamientos no son universalistas, por lo cual acepta y promueve la pluralidad de métodos, que serán universales en el sentido de adaptabilidad y no como verdades únicas o leyes inamovibles. Este enfoque se considera gobernado por un sistema metodológico abierto dado que no todas las variables y sus relaciones son conocidas o conocibles, por lo que no se conoce o será conocible el límite del modelo (Jespersen, 2009).

El enfoque babilónico también presenta una postura orgánica que tiene en cuenta que el sistema en estudio está bajo continuo cambio, y que en su interior la compleja red de interdependencias de las partes que lo componen ponen en entre dicho el establecimiento de axiomas universales de comportamiento individual y mucho menos a nivel global, siendo esto una base de crítica a la microfundamentación en la macroeconomía. Además, un ejemplo de la pluralidad del enfoque puede evidenciarse cuando se trata de lidiar con el error de pronóstico y no eliminarlo mediante propiedades estadísticas ${ }^{13}$.

\section{Dicotomía metodológica en los modelos macroeconómicos}

Tomando prestada la clasificación elaborada por Sheila Dow (1998) se realizará un análisis de la dicotomía metodológica en macroeconomía encarnada en dos de las cuatro categorías propuestas por ella, el mainstream y el post keynesianismo. El Marxismo y La Escuela Austriaca se dejan de lado por simplificación en la explicación, tratando de evidenciar las diferencias significativas entre las dos formas de pensar seleccionadas.

Por un lado, las escuelas herederas del pensamiento de Pigou de comienzos del siglo, el mainstream, las cuales comparten su confianza en el poder estabilizador de los precios y por ende en los mercados, además de resaltar su excesivo nivel de abstracción que se evidencia en cuestiones como la neutralidad del dinero, la inefectividad de la políticas de demanda o el ajuste automático derivado de la incorporación de las expectativas racionales, por otro lado, tenemos la escuela post keynesiana que en líneas generales percibe que la economía no logra de forma automática el uso pleno de los factores, por lo que resalta el rol de la demanda efectiva para la conquista de ese objetivo. Aunque lo más relevante es que los post keynesianos descansan sus modelos sobre la realidad resaltando el papel de cuestiones como el desempleo involuntario como un rasgo permanente y no de corto plazo en las economías modernas.

13. Esta idea permitirá recoger la incertidumbre fundamental Post Keynesiana distinta del manejo estocástico de las expectativas racionales sobre este fenómeno. 
Figura 1.

\section{Panorama de las escuelas macroeconómicas más relevantes divididas de acuerdo a la posición metodológica}

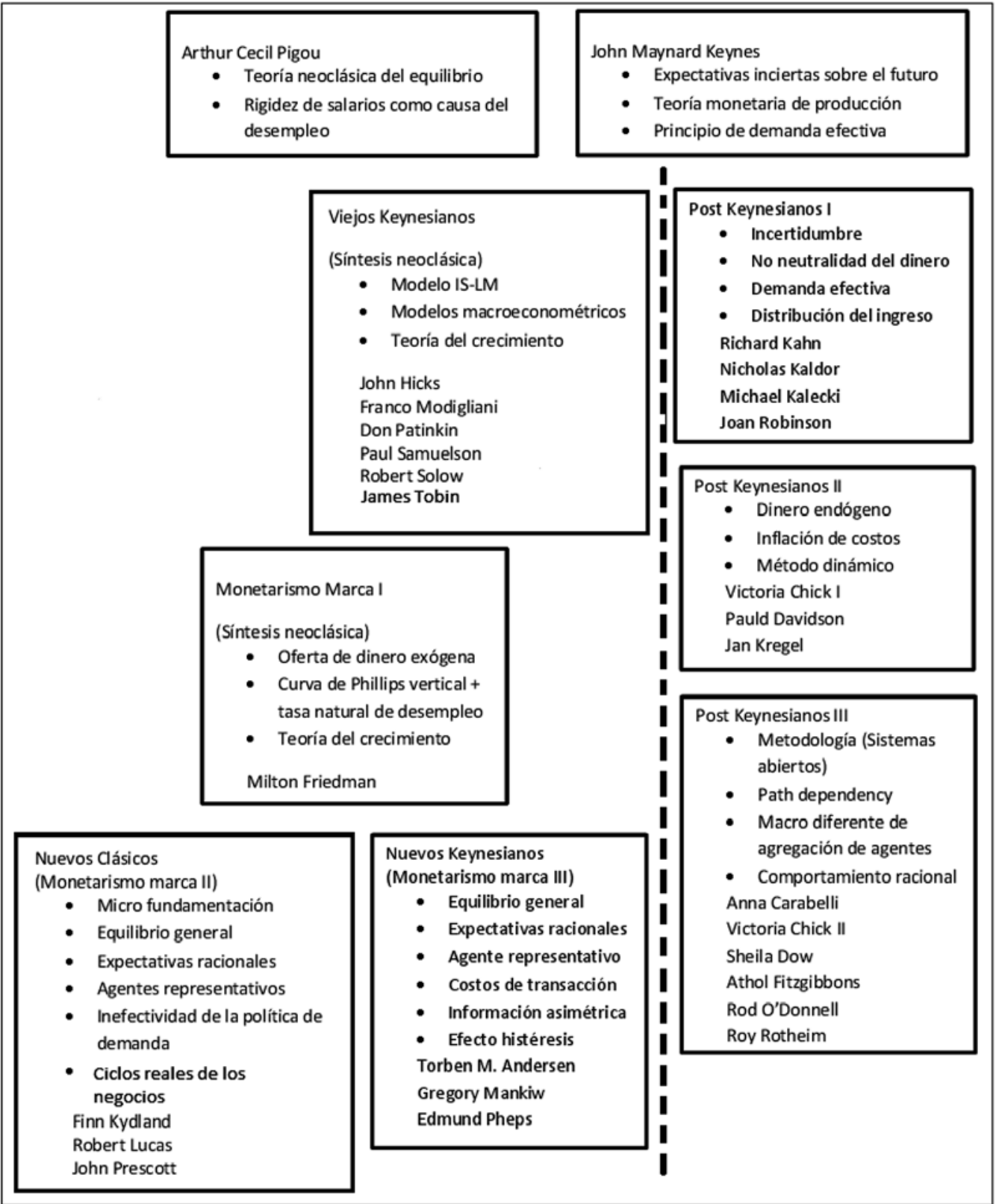

Fuente: Jespersen, 2009, p. 16 (Trad. propia). 
La mencionada dicotomía puede detallarse aún más en la figura 1, que muestra del lado izquierdo las escuelas neoclásicas desde el modelo Clásico de Pigou, pasando por los Monetaristas de Friedman, hasta las versiones más actuales de NMC, $\mathrm{NMK}^{\mathbf{1 4}}$ y RBC, que han profundizado sus aparatos analíticos y sofisticación matemática lo que se evidencia en la sofisticada axiomática.

Los post keynesianos ${ }^{15}$ por su parte muestran tres marcas o etapas de desarrollo desde los autores originadores como Kalecki, Kaldor o Robinson hasta los más recientes con énfasis en temas de metodología como Victoria Chick y Sheila Dow, puede observarse los modelos de esta escuela se encuentran anclados a fenómenos reales que constituyen la hipótesis de arrancada en aspectos como la incertidumbre, los problemas de agregación, el desempleo, el dinero endógeno o la no neutralidad del dinero. Aunque sabemos que hacer un modelo siempre necesita de cierta abstracción, los post keynesianos tratan de validar hechos ontológicos dentro de los mismos.

Ahora bien, luego de hacer evidente tal dicotomía se procederá a explicarla en términos metodológicos. Respecto de los modelos macroeconómicos ortodoxos se encuentra que su debilidad radica en que son construidos a partir del método hipotético deductivo, que menciona como el proceso de creación teórica depende de un cálculo abstracto, y la verdad lógica del razonamiento deductivo no depende de la verdad fáctica de las premisas (Blaug, 1980) ${ }^{\mathbf{1 6}}$.

Lo anterior se refleja en el hecho que la construcción epistemológica de los modelos macroeconómicos mainstream nunca abandona el mundo analítico o abstracto, desde el planteamiento de los axiomas o premisas, pasando por la elaboración de la teoría, hasta su materialización en recomendaciones de política económica.

Los axiomas que constituyen la base del modelo no tienen ningún anclaje en la realidad, sino que funcionan como acotadores del problema, que permiten visualizar el sistema ideal de mercado en su más pura expresión libre de fricciones.

14. Para algunos lectores podría sonarles extraño que el modelo NMK sea considerado neoclásico. No obstante, luego de saber que el propio Mankiw, uno de los autores representantes de esta escuela, negara cualquier conexión de sus explicaciones con la Teoría General de Keynes de (1936) por considerarlo un libro oscuro para sus propósitos. Lo anterior, deja en evidencia que la Nueva Macroeconomía Keynesiana nada tiene de Keynesiana pues no es más que la estructura de equilibrio general walrasiano de la NMC con rigideces de precios. Según Snowdon y Vane (2005), Cencini (2005), la NMK buscó mostrar algunos principios keynesianos de no neutralidad del dinero, efectividad de las políticas de demanda y desempleo involuntario a través de la rigidez nominal y real de los precios con base en microfundamentación de competencia imperfecta, es por ello que el keynesianismo es resaltado de rigideces contrario a lo que opinaba el mismo Keynes (1936) respecto de la posibilidad de desempleo con flexibilidad de precios.

15. Según Lavoie (2006) los Post Keynesianos no son una escuela homogénea que se divide en tres vertientes. La primera es la seguidora de Keynes y sus obras más representativas como la famosa Teoría General de 1936, y el Treatrise on money de 1930 y el Treatise on probability de 1921. En segundo lugar, están los seguidores de Kalecki que en temas relacionados con el ciclo, el crecimiento y la distribución del ingreso en condiciones de desempleo. Y finalmente, los continuadores de la obra de Sraffa, los cuales se han hecho llamar Neoricardianos.

16. Supone que el conocimiento científico está constituido de una estructura lógica que presenta una ley universal, más una serie de condicionantes iniciales relevantes que en conjunto constituyen las premisas, de las cuales se deducen las afirmaciones acerca del fenómeno que se trata de explicar. 
Dentro de estos encontramos el individualismo metodológico, la racionalidad de los agentes, la plena flexibilidad de precios, el análisis marginal y el principio de sustituibilidad bruta.

A partir de las condiciones iniciales, se garantiza la existencia de un equilibrio general el cual permite construir una sólida y coherente estructura matemática teórica que constituye el pilar de la macroeconomía moderna walrasiana. Luego se realizan las prescripciones de política económica que buscan acercar el mundo real a su versión ideal, por lo que tales recomendaciones constituyen una serie de procedimientos para reducir las fricciones en el mercado dentro de las cuales encontramos como ejemplo la flexibilización de precios especialmente en el mercado de trabajo.

Un ejemplo de la puesta en práctica del método hipotético deductivo en macroeconomía se puede observar en el trabajo de Milton Friedman, uno de los principales representantes del mainstream, más específicamente, el líder del programa de investigación Monetarista. Como es sabido, Friedman (1953) deja claro en su Essays in positive economics que la teoría y sus supuestos deben ser abstractos y no necesariamente vinculados con hechos comprobables u observables en la realidad.

Friedman justifica lo anterior argumentando que las teorías son una combinación compleja de dos elementos: el primero es el lenguaje científico que permite establecer el procedimiento de razonamiento deductivo estableciendo enunciados analíticos normalmente formales; el segundo es organizar de manera sistemática el contenido empírico para validar las hipótesis establecidas en la teoría, buscando obtener predicciones cercanas a la realidad.

Este último paso encierra la lógica metodológica que se ha efectuado desde J.S. Mill, consolidada en el famoso ensayo de L. Robbins en 1932, y que busca mediante razonamiento deductivo aislar los fenómenos económicos relevantes de otros efectos que hacen perder de vista al investigador el verdadero problema. Estos eventos relevantes se consideran como leyes de conducta económica, como la Ley de la Demanda, que pueden ser descubiertas por la mente humana luego de un arduo proceso de razonamiento, que se vale de supuestos abstractos para hallar un resultado objetivo, para finalmente corroborar sus resultados haciendo predicciones sobre los fenómenos estudiados.

En definitiva para Friedman los supuestos son instrumentos, de allí el nombre instrumentalista, o herramientas que le permiten al investigador develar los mecanismo de causalidad de los fenómenos económicos, y por ende, deben ser juzgados como eso, como instrumentos abstractos que no deberían ser validados en la realidad (Scarano, 2001).

No obstante, como se mencionaron antes los modelos macroeconómicos post keynesianos gozan de una estructura metodológica diferente, ya que no son desarrollados bajo el esquema hipotético deductivo sino bajo el proceso de retroducción ${ }^{17}$

17. El proceso anterior desarrollado por Lawson (2003) recibe el nombre de retroducción o abductivo, pues consiste en una cadena de retroalimentaciones que arranca en la realidad, luego viaja a lo analítico, para nuevamente volver al escenario real y ser puesta a prueba. 
del realismo crítico. La retroducción o abducción es una forma de ver cómo se combina la inducción a través de la observación y regularidades del mundo real, con el razonamiento lógico deductivo del mundo analítico, para garantizar que la teoría se subordine a la realidad (Jespersen, 2009).

La retroducción se presenta en la figura 2 donde el proceso de creación de conocimiento en macroeconomía aparece como una intrincada relación de tres mundos, el real, el analítico y el operacional. La metodología de la retroducción establece una secuencia lógica de pasos, primero se hace una descripción del campo objetivo denominado revisión ontológica ${ }^{\mathbf{1 8}}$, segundo se indaga por la manera cómo se debe organizar el análisis en forma consistente por medio de una teoría para desarrollar la hipótesis en busca de relaciones causales que sustituye el análisis de meras tendencias. Luego, la teoría es sometida a comprobaciones empíricas más robustas, y contrario al instrumentalismo, el mejor criterio para evaluar un modelo analítico no es la predicción basada en leyes de comportamiento sino en su relevancia práctica en el mundo tres cuando la política económica es capaz de alterar la realidad. En definitiva los post keynesianos por medio de esta metodología logran incorporar de manera más cercana a la realidad una serie de temas neurálgicos propios de la ontología macroeconómica, en contraste con la axiomática ortodoxa.

Figura 2

\section{Realismo crítico: proceso de retroducción}

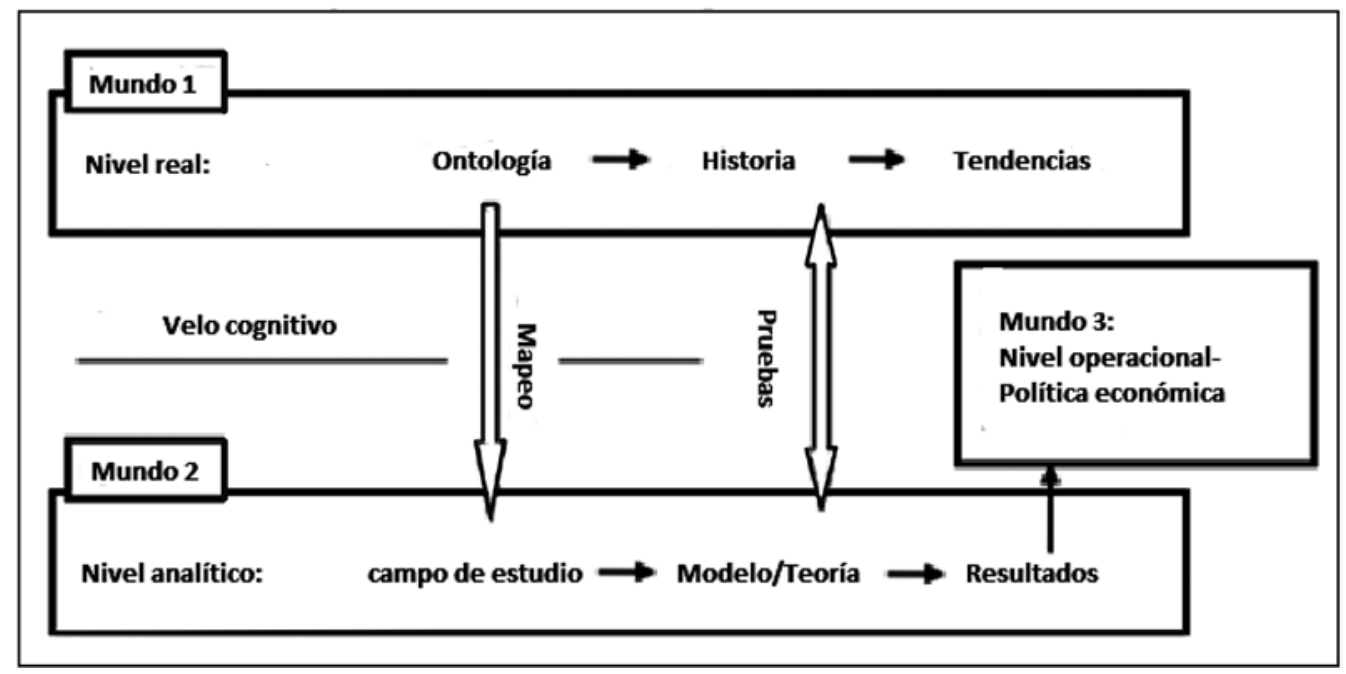

Fuente: Jespersen, 2009, p. 54.

18. Lawson (2003) define la ontología como la investigación del ser, su existencia, su naturaleza, constitución y estructura. La ontología de la macroeconomía sería el estudio de los hechos que caracterizan de forma detallada los macro actores, macro mercados y macro que lo componen (Jespersen, 2009). 
Así pues, los modelos macroeconómicos pueden ser divididos bajo dos esquemas metodológicos diferentes que pueden ser representados en la figura 3 , por un lado, se observa que los modelos neoclásicos surgen con axiomas muy restrictivos que garantizan una solución consistente, matemática y lógica, del modelo. Sin embargo, el nivel de abstracción necesario para obtener tales resultados elimina buena parte de su capacidad de explicación de los fenómenos que estudia, por ello, desde su origen axiomático, pasando por la construcción del modelo, y luego en la puesta en práctica de la política donde usualmente se sugiere acomodar la realidad a la pureza del modelo, la explicación metodológica del equilibrio general nunca abandona el mundo analítico y de lo abstracto, por el contrario, la versión post keynesiana arranca en el mundo real con la revisión ontológica, luego a partir de los hechos evidenciados construye su modelo analítico/teórico, que finalmente muestra su validez cuando es puesto a prueba en el mundo operacional por medio de la política económica.

Figura 3

\section{Dicotomía metodológica en macroeconomía}

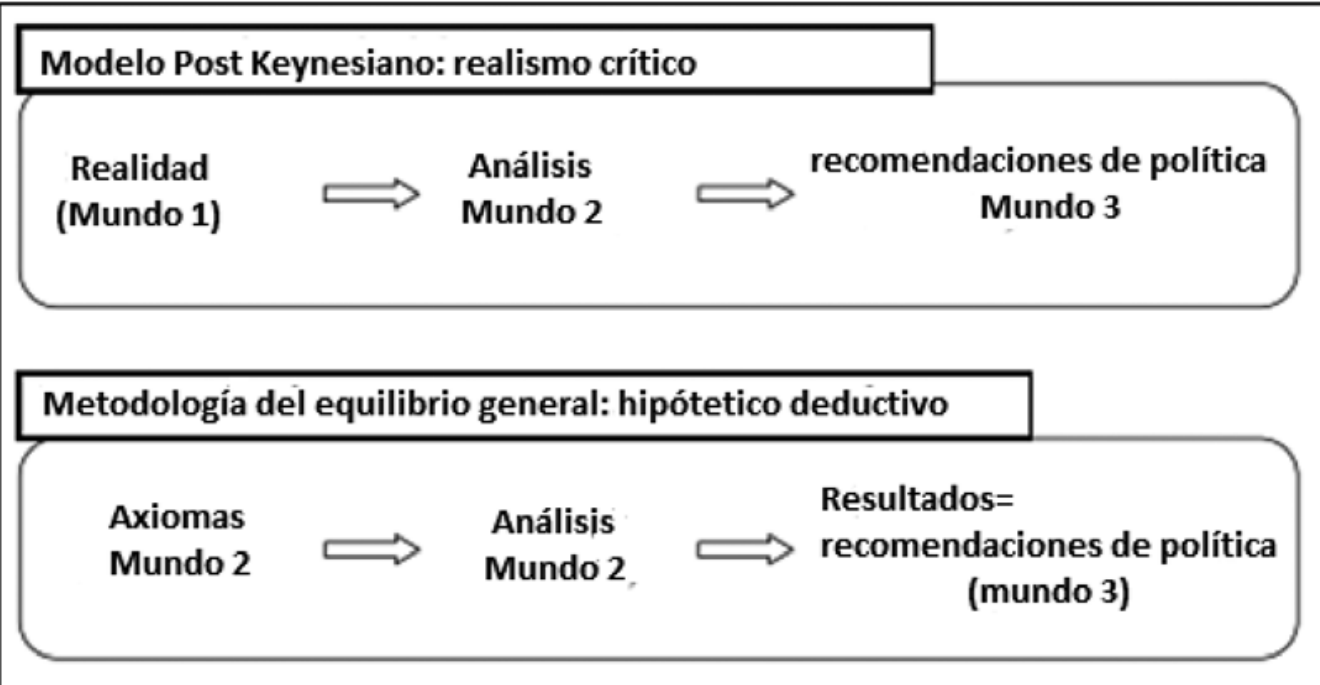

Fuente: Jespersen, 2009, p. 81.

Al igual que la experiencia de Friedman ejemplifica bien la metodología mainstream, también se puede mirar el trabajo de algunos autores post keynesianos para estudiar su modo de construir conocimiento, por un lado, la Teoría General constituye un buen ejemplo de procedimiento metodológico desde el realismo crítico, lo que se puede explicar con la analogía que hace Chick (1990) de la obra de Keynes con una obra de teatro con múltiples actores y escenas, donde cada escena desarrolla una acción específica de un área de la economía como el consumo o la inversión en la cual entran algunos actores mientras que el resto se mantiene 
fuera del escenario (ceteris paribus) hasta que aparecen en el acto final todas las partes pueden interactuar.

Lo anterior hace alusión a la diferencia entre sistemas abiertos y cerrados en el argot de la metodología científica. El sistema cerrado es asociado a un esquema controlado artificialmente mediante supuestos que aíslen el modelo de posibles fricciones. El modelo de equilibrio general es presentado como una expresión de lo anterior, pues luego de establecer los axiomas se establece una serie de procedimientos, al estilo de laboratorio en las ciencias duras, que crean un mundo artificial el cual constituiría la realidad analítica, muy al estilo instrumentalista, por otro lado, los sistemas abiertos que tratan de recoger la compleja naturaleza del campo de investigación que se manifiesta incompleto pues no le conocemos totalmente y está en continuo cambio.

Lo que resalta Chick (1990) es que Keynes introdujo una metodología de sistemas semi cerrados, es decir, durante algunas secciones de su libro congelaba algunos conceptos, usando el ceteris paribus, tratando de aislar analíticamente el problema, pero al final eliminó buena parte de estos supuestos en el capítulo 18, que en palabras de Chick (1990) haría las veces de acto final, para tener una explicación general del problema de la ocupación y la producción. Uno de los rasgos más importantes de Keynes de 1936 es que toda la explicación nace de una reflexión ontológica basada en la crisis mundial de 1929 y los problemas anteriores del Reino Unido en el periodo entre guerras.

\section{Mismos interrogantes respuestas diferenciadas}

La forma en que se acercan los modelos macroeconómicos a los fenómenos que estudian difiere de acuerdo a los esquemas metodológicos adoptados que genéricamente se reconocen en las visiones Euclidiana/Cartesiana y Babilónica, y que se materializan en los modos de pensar macroeconómicos: mainstream y post keynesianos. Los fenómenos como el desempleo, la inflación, los desequilibrios en la balanza de pagos, los ciclos económicos, entre otros, son capturados de manera diferenciada dependiendo de qué tan abierto o cerrado sea el sistema metodológico, lo cual se evidencia en su nivel de abstracción, cercanía con la realidad respecto de cuestiones como la noción de tiempo (expectativas), equilibrio, dinero y microfundamentación.

Respecto de la incertidumbre, por ejemplo, el mainstream la asocia con el riesgo, es decir, que el futuro de los eventos macroeconómicos es concebido como inmutable y totalmente predeterminados por leyes similares a la ley de gravitación que gobierna los cuerpos celestes. Esto se materializa en modelos de comportamiento donde puede conocerse de ante mano el vector de precios de equilibrio por los individuos totalmente racionales, que tienen información perfecta y completa que actuarían conforme el modelo predice asegurando el ajuste hacia el equilibrio de pleno empleo. Todo lo anterior se refleja con la incursión de las expectativas 
adaptativas de la escuela monetarista $\mathrm{I}^{\mathbf{1 9}} \mathrm{y}$ las expectativas racionales propias de la NMC, RBC y NMK.

Además, como la pieza angular del mainstream es el agente representativo, en el agregado la incertidumbre macroeconómica puede reducirse a riesgo probabilístico individual bajo una serie de condiciones muy restrictivas dado que se debe conocer de ante mano el conjunto de posibles resultados futuros derivado de las acciones presentes, a su vez la probabilidad matemática debe ser idéntica y conocida para todos los individuos, y bajo tales condiciones se acude a la Ley de los Grandes Números replicando cada decisión económica n veces, suponiendo que cada decisión es independiente de la anterior, se tiene que los eventos inciertos terminan siendo comportamientos altamente predecibles (Jespersen, 2009).

Lo anterior se materializa en la Teoría de las Expectativas Racionales -TER-, y puede ejemplificarse mediante la formación de la expectativa sobre los precios:

$$
\text { 1. } P_{t}^{\theta}=E\left[P_{t} \mid I_{t-1}\right]=E_{t-1} P_{t} ;\left\{\begin{array}{c}
P_{t}^{\theta}: \text { Expectativa subjetiva } \\
E\left[P_{t} \mid I_{t-1}\right]: \text { Expectativa objetiva }
\end{array}\right.
$$

La condición anterior expresa la expectativa sobre los precios cuando toma la forma de una distribución de probabilidad en lugar de un valor particular de predicción. Esta es la versión fuerte de TER donde las expectativas de los agentes sobre variables económicas coincidirán con la verdad o esperanza matemática de la variable condicionada al conjunto de información un periodo antes, en otras palabras, el individuo representativo racional toma la información disponible acerca de los factores que determinan el comportamiento de la variable a pronosticar (It-1), por lo que descubre el modelo económico correcto que se traduce en una verdad objetiva para el individuo representativo y el agregado (Heijdra y Van Der Ploeg, 2002). En ese sentido, esta teoría, deduce leyes inermes y ocultas que gobiernan los comportamientos de los agentes económicos, supone una realidad económica pre programada y predeterminada, por lo que la futura trayectoria de la economía y sus posibles consecuencias son previamente conocidas y pueden describirse bajo una estable función objetiva de probabilidad condicional.

Así, la TER se muestra compatible con la estructura euclidiana/cartesiana basada en el razonamiento lógico abstracto que establece axiomas, como base de las leyes de comportamiento que sirven para predecir el comportamiento de las variables relevantes. El conjunto de características descritas anteriormente, es lo que Paul Davidson (2011) describe como hipótesis de ergodicidad ${ }^{\mathbf{2 0}}$, donde los individuos toman decisiones congruentes con el modelo macroeconómico subya-

19. Las expectativas adaptativas reflejan el espíritu de ajuste automático ante desequilibrios macroeconómicos pero no comparte la estructura de probabilidad condicionada dado que se construye como un promedio ponderado de los datos del pasado de la variable pronosticada.

20. Samuelson denominó la hipótesis de ergodicidad a un término tomado de la estadística mecánica del cual se entiende que la realidad económica futuro se concibe como inmutable en el sentido de que la futura trayectoria de la economía y las futuras consecuencias de todas las elecciones de los individuos están previamente predeterminadas (Palsson, 2012). 
cente conduciéndolos a conocer de antemano el vector de precios de equilibrio. Es por ello que estos modelos suponen que la economía es inherentemente estable y sus proyecciones permiten estabilizar cualquier desequilibrio real llevando la economía al pleno empleo ${ }^{21}$.

Para los post keynesianos las expectativas no son una herramienta epistemológica adicional al andamiaje teórico, sino un rasgo ontológico básico en la toma de decisiones en las economías de mercado bajo incertidumbre. La incertidumbre para esta escuela no es equivalente al riesgo dado que se supone que la estructura económica está en continuo cambio y las decisiones de los individuos generan reacciones en otros a través de la interacción social con consecuencias impredecibles. En general, simplemente no se puede conocer con certeza nada sobre el futuro pues este será construido continuamente por las decisiones de los agentes evitando la posibilidad de cálculo probabilístico, es decir, el mundo es no ergodico.

Figura 4

Anatomía de conocimiento individual bajo incertidumbre

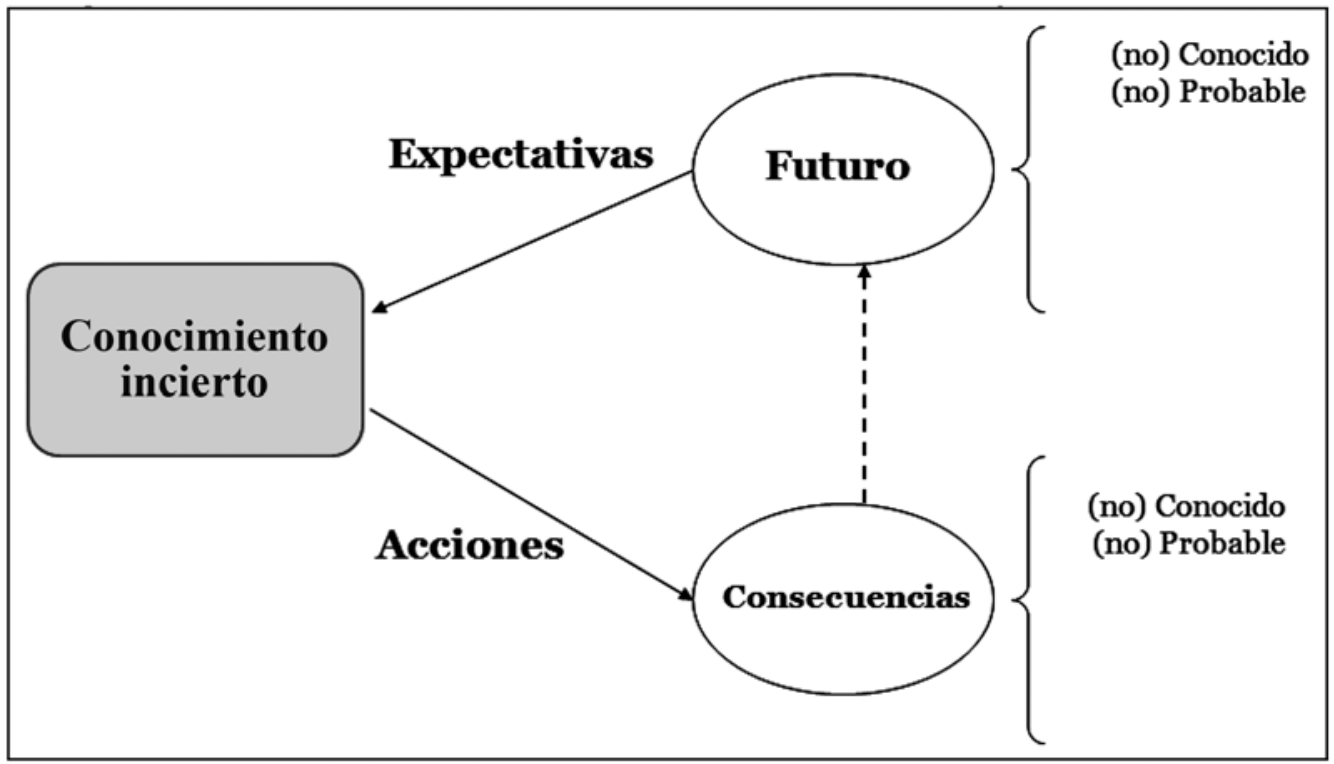

Fuente: Jespersen, 2009, p. 112

En la figura 4 se aprecia como la función de probabilidad futura no puede ser conocida de antemano pues inicialmente las expectativas son formadas en

21. Una aplicación del ajuste de las expectativas racionales es la explicación ciclo según la NMC, que sucede por choques agregados de demanda resultado de un cambio no anticipado de la oferta monetaria, los cuales afectan a toda la economía causando errores en la formación de las expectativas sobre los precios (racionalmente formadas), lo que causa que la producción y el empleo se desvíen de su nivel de largo plazo o natural (información completa). 
un entorno de conocimiento parcial o nulo del futuro, por lo que los individuos racionales, con información incompleta, tratan de seguir convenciones sociales o simplemente seguir su instinto para tomar decisiones, que de una u otra manera, generarán consecuencias inesperadas, incluso para los mismos agentes que tomaron la decisión pues en el mercado la interacción hace que cada decisión individual provoque reacciones en otros haciendo que el agregado no coincida con la suma de las acciones individuales, traduciéndose en una seria crítica al individualismo metodológico y la microfundamentación, lo que se discute más adelante. Así, contrario al mainstream los post keynesianos creen que el largo plazo es una situación borrosa, difusa e impredecible conforme el tiempo calendario pase ${ }^{22}$, y por el contrario, lo más conocido es el corto plazo dado que tenemos información reciente que nos permite imaginar la trayectoria que seguirán las variables.

Para Keynes $(1936,1937)$ los cambios exógenos ${ }^{\mathbf{2 3}}$ en el estado de confianza de los empresarios a corto plazo puede suscitar fluctuaciones significativas de la rentabilidad monetaria de los proyectos, haciendo fluctuar la inversión, la producción y el empleo. En este sentido, la economía no tiende de manera automática al pleno empleo (largo plazo mainstream) sino que la trayectoria de la economía es definida por el camino tomado por la economía a corto plazo, en otras palabras, para el Post Keynesianismo el largo plazo se constituye de una secuencia de cortos plazos. Lo anterior significa que no existe el largo plazo como centro de gravedad y mucho menos con garantía de uso pleno de los recursos productivos. En general los post keynesianos cuando incorporan la incertidumbre en sus modelos no tratan de eliminarla o minimizarla como si lo hace el mainstream.

Por otro lado, la incertidumbre para los post keynesianos hace que en las economías modernas prospere el uso del dinero como activo que cubre ante eventuales pérdidas de capital, además denomina los contratos que actúan como garantes de las transacciones, y también permite a las empresas cuantificar los ingresos y gastos proyectados lo que determina el volumen de empleo individual y agregado.

Contrariamente, la visión neoclásica pura de intercambio incorpora el dinero como otra mercancía que se suma al sistema en lugar de considerarlo una pieza esencial del mismo. De hecho, en el mainstream los agentes racionales no tendrían por qué demandar dinero si conocieran de antemano la función de probabilidad futura de rendimientos de activos financieros dado que es un activo que no tiene un rendimiento financiero. La única forma de demandarlo es introduciendo imperfecciones en la elección de portafolios como lo hace la NMK.

22. Los Post Keynesianos diferencian la noción de tiempo de sus modelos con la presentada en la estructura neoclásica, para los primeros el tiempo se denomina histórico, su principal característica es la no reversibilidad por lo que la economía puede seguir múltiples trayectorias dependiendo del camino tomado en el pasado. La noción de tiempo mainstream es el tiempo mecánico donde se describe los pasos lógicos que deben seguir las variables para avanzar a su trayectoria de largo plazo (Henry, 2003).

23. Las expectativas keynesianas son consideradas como exógenas a los individuos y provienen más de cambios erráticos en la confianza de los agentes económicos, admitiendo la importancia de lo irracional en las decisiones económicas. Las expectativas racionales y adaptativas se consideran endógenas al comportamiento racional del individuo maximizador, por lo que el resultado de sus pronósticos es consistente con el equilibrio (Dow, 1998). 
Para los post keynesianos, por su parte, el ingreso ganado se destina a bienes de consumo o activos líquidos. Si estos activos son no producibles y no sustituibles por el resto de bienes de la economía ${ }^{24}$, la demanda por estos activos líquidos no tiene porqué crear demanda por los bienes del sector real (Davidson, 2011).

Así pues, los incrementos en el ingreso que derivan en ahorro no se traducen en demanda a través de la inversión sino que quedan ociosos en activos financieros afectando el nivel de empleo y producción agregados. Entonces se muestra como en una economía monetaria de producción no existe un mecanismo que garantice que todos los pagos terminen en demanda de bienes, por lo que los empresarios no saben si pueden recuperar sus inversiones y ganar.

Adicionalmente, el dinero en los post keynesianos se integra a la economía a través de la producción y no por medio del intercambio, es por ello que los incrementos en el ingreso, que traen consigo mejoras en la rentabilidad de los proyectos de inversión productiva, estimulan la creación de dinero por medio de la expansión del crédito (expansión secundaria del dinero) del sector financiero. En ese sentido el dinero es endógeno al proceso productivo a través del financiamiento de la inversión empresarial, por lo que desaparece la distinción propia de la dicotomía clásica entre sector real y nominal, la figura de los mecanismos de transmisión y la existencia de neutralidad del dinero. Los rasgos anteriormente descritos quedan recogidos de mejor manera en la tabla 2 donde Lavoie (1992) discrimina entre el mainstream y los post keynesianos la visión de cada forma de pensar sobre el rol del dinero en la economía.

Un rasgo adicional que diferencia metodológicamente al mainstream del post keynesianismo es la noción de equilibrio que cada uno incorpora en sus modelos, para el mainstream el deseo por explicar el funcionamiento de una economía descentralizada de mercado recibió como respuesta una demostración formal en el trabajo de Arrow y Debreu (1954), cuando se demostró la solución matemática del modelo de equilibrio general. Este trabajo constituyó la base de los nuevos modelos macroeconómicos micro fundamentados, los cuales comparten alrededor de la noción del equilibrio la consistencia lógica y matemática, la asociación con el vaciamiento de mercados y que éste actuaba como centro de gravedad ante perturbaciones de corto plazo.

24. Según Davidson (2011) y Dow (1998) estos dos esencias básicas no ortodoxas se encuentran en Keynes las cuales se pueden postular como: i. la elasticidad de la productividad de los activos líquidos y el dinero es cero o insignificante, ii. la elasticidad de sustitución entre activos líquidos (incluyendo el dinero) y los bienes reproducibles es cero o insignificante. Lo primero significa que cuando la demanda de dinero aumente, los empresarios no podrán contratar para producir dinero, asegurando una estabilidad en el valor del dinero respecto de los bienes. El segundo asegura que la parte del ingreso que no se consume encuentre lugar en los activos no producibles. La existencia de esos bienes no reproducibles que pueden ser demandados para aguardar el ahorro significa que todo el ingreso generado de la producción, en el corto y largo plazo, no se traduce en bienes generados por el trabajo. 
Tabla 2

\section{Características del dinero en los programas de investigación neoclásico y post keynesiano ${ }^{25}$}

\begin{tabular}{|l|l|l|}
\hline \multicolumn{1}{|c|}{ Características } & \multicolumn{1}{c|}{ Teoría neoclásica } & \multicolumn{1}{c|}{ Post Keynesiana } \\
\hline El dinero entra... & Intercambio & Producción \\
\hline El dinero es... & Requerimiento individual & Convención social \\
\hline Dinero & Dado como dotación (Stock) & Flujo \\
\hline Dinero es... & Exógeno & Endógeno \\
\hline Las tasas de interés son... & Endógenas & Exógenas \\
\hline Foco de análisis & Sustitución y efectos de portafolio & Efecto ingreso y pasivos \\
\hline
\end{tabular}

Fuente: Lavoie, 1992

Una característica de los modelos mainstream es que pierden toda su capacidad explicativa una vez la economía alcanza el equilibrio, lo que se explica en la dualidad entre variables exógenas y las endógenas donde la capacidad explicativa recae en las primeras con el agravante que por ser exógenas no sabemos nada ellas (Dow, 1998). Adicionalmente, las situaciones de desequilibrio inducidas por choques exógenos no afectan la posición de equilibrio posterior a los mencionados shocks, es decir, los equilibrios están previamente prefijados y no pueden ser alterados por la trayectoria de las variables, situación conocida como path independence (Arestis y Sawyer, 2009).

Lo anterior se explica por la noción de tiempo que maneja el mainstream, y constituye un rasgo fundamental en la caracterización del equilibrio en términos metodológicos. Bajo esta estructura se estudia el equilibrio con la definición de tiempo lógico que únicamente establece una secuencia de causalidad entre variables, y muestra los mecanismos de ajuste ante perturbaciones garantizando que las variables retornen a su posición pre establecida de equilibrio a largo plazo (Henry, 2003). Esto tiene como consecuencia que los choques que sufra la economía sean reversibles, por ello el ciclo es entendido como una desviación aleatoria alrededor de la tendencia de largo plazo, lo que constituye un rasgo fundamental de la ortodoxia y de esta noción de tiempo.

Por el contrario, la visión post keynesiana tiene reservas sobre el estudio de la economía en condiciones de equilibrio dado que la revisión ontológica del campo de investigación macroeconómico muestra la persistencia del desempleo, inestabilidad de precios y desbalances externos y públicos, para esta escuela no se puede pensar en equilibrio cuando todo el sistema está en constante cambio

25. En Lavoie 1992 no se presenta la segunda columna como Post Keynesianismo sino como programa post clásico dado que se puede incorporar el pensamiento neo ricardiano, y además las visión Post Keynesiana puede ser incorporada dentro de una tradición larga que ha reflexionado por más de 200 años alrededor de estos problemas. 
aunque algunos indicadores macroeconómicos parecen reflejar cierta estabilidad. De hecho, Kaldor (1972) resalta como la economía neoclásica ha concentrado su atención en la fuerzas del mercado que promueven el equilibrio olvidando aquellas que promueven el cambio y la evolución. A pesar de la aparente incongruencia de los hechos con la instrumentación analítica del equilibrio, la noción de éste puede ser modificada para entender la realidad.

Por un lado, el equilibrio puede ser no entendido como sinónimo de vaciamiento sino como estado de no cambio o estabilidad de una situación, es decir, que no existen fuerzas automáticas de corrección de desequilibrios. Esta descripción se aplica a la visión de equilibrio en Keynes cuando trataba de describir la persistencia del desempleo en niveles elevados por problemas de demanda efectiva durante la crisis de finales de los 20's. En ese sentido, equilibrio no significa vaciamiento.

Por otro lado, la noción de equilibrio en los post keynesianos puede ser alterada a través de la incorporación de la incertidumbre junto con la definición del tiempo histórico en lugar de su expresión mecánica/lógica. La incertidumbre sobre el futuro muestra como la trayectoria de las variables no está previamente definida, por lo que el camino que siga la economía es construido continuamente en un proceso path dependency, cuya idea principal puede ser vista de la siguiente manera: cualquier decisión que una agente tome, abre en el futuro muchas situaciones alternativas, pero solo una de ellas se elegirá lo que se puede ver en la figura 5.

Figura 5, path dependency

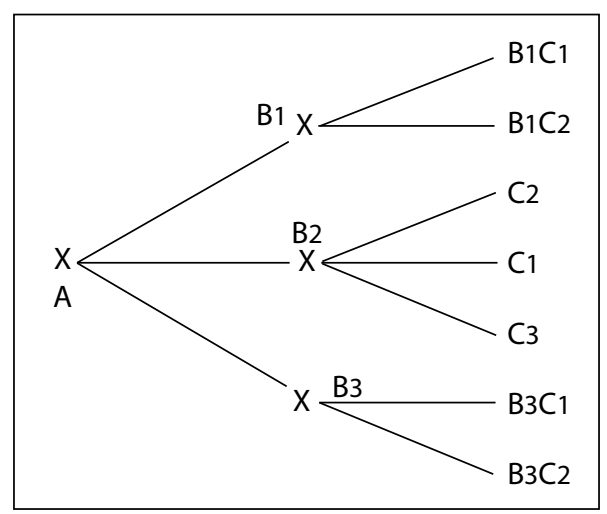

Fuente: Arestis y Sawyer, 2009.

En la figura anterior se aprecia cómo la economía estando en una posición inicial (A) puede tomar múltiples trayectorias como abrirse a la economía mundial de forma unilateral (B1), promover la intervención estratégica de sectores (B2) o seguir sin hacer nada (B3). Cada una de esas situaciones tiene como característica la no reversibilidad, y a su vez la posibilidad de alcanzar otro tipo de escenarios, además de no asegurar el uso pleno de los factores, por esto bajo el post keynesianismo el largo plazo es consecuencia de una cadena de cortos plazos no necesariamente 
pre establecidos. Ejemplo de lo anterior puede ser los procesos de acumulación causativa de Gunnar Myrdal y la histéresis en el de desempleo como sucedió en Europa según Mitchell y Muysken (2008) y Reinert (2012). En definitiva, el path dependency permite mostrar procesos de acumulación virtuosos y viciosos.

Otra de las características más relevantes de la macroeconomía es la forma en que relaciona los agregados con las partes que los componen, por un lado, se tiene la microeconomía walrasiana del mainstream que ha hecho equivalente la conducta del agente representativo optimizador con el agregado, por lo que la teoría general sería la microeconomía y la macroeconomía se convertiría en un caso especial de la misma a través del modelo de equilibrio general walrasiano. Esto es evidente en las teorías del consumidor, inversión, mercado de trabajo, demanda de dinero, etc.

Lo anterior, se dio en la macroeconomía con los desarrollos de Lucas a comienzos de los 70's con la hipótesis de las expectativas racionales y el modelo de percepciones erróneas que explica el ciclo basado en fallo de naturaleza microeconómica, como es la asimetría en la información. La escuela RBC fue aún más lejos pues las fases descendentes del ciclo con caídas de la actividad económica e incrementos en la tasa de desempleo son percibidas como fruto de decisiones óptimas intertemporales de asignación trabajo a partir de fluctuaciones de la productividad y por ende del salario real. La competencia imperfecta también fue incorporada a la estructura general walrasiana para explicar las rigideces de precios reales y nominales que evita a corto plazo que los mercados se ajusten rápida y completamente, lo que se manifiesta en desempleo involuntario en presencia de expectativas racionales en la $\mathrm{NMK}^{26}$.

Por otro lado, la microfundamentación post keynesiana propia de la visión Babilónica pues reconoce múltiples y complejas relaciones entre los agregados y sus partes. En ese sentido, la microfundamentación derivada de Keynes, por ejemplo, reconoce que bajo condiciones de incertidumbre los individuos son influenciados por convenciones sociales derivadas de comportamientos de grupos por lo que prima en esta escuela el holismo en lugar del individualismo metodológico.

Entonces, se podría pensar que la suma de las partes que componen el sistema reflejaría el resultado global,no obstante, para los post keynesianos la interacción en el mercado hace que las decisiones individuales tomadas de manera aislada cambien por la influencia que tienen los grupos sobre las conductas individuales.

Cynamon y Fazzari (2012) menciona al respecto que el comportamiento del consumo en Estados Unidos durante los últimos treinta años evidencia como la clase media ha sido bombardeada a través de los medios de comunicación (especialmente los más recientes como el internet y la redes sociales) a llevar el estilo de vida ostentoso de las clases más privilegiadas con dos agravantes: una concentración del ingreso elevada y un incremento en la innovación de productos financieros de crédito, lo que derivó en un endeudamiento muy superior al ingreso per cápita, lo

26. Un ejemplo de lo anterior es la teoría de los salarios de eficiencia donde se muestra como el proceso de optimización de la firma la lleva a pagar un salario real más alto al de equilibrio por lo que la maximización individual de la firma no es compatible con el uso pleno de los recursos a nivel macroeconómico (Snowdon y Vane, 2005). 
que creó una fragilidad inminente en el sistema que estalló con la crisis de 2008. El punto es que las teorías del consumo basadas en el individuo optimizador como las de Modigliani y Friedman se equivocan pues las elecciones de los individuos están relacionadas con la identidad formada en su experiencia y con el grupo de personas que se relaciona. Así la suma de las decisiones de las partes por separado no refleja el resultado del agregado.

Por lo anterior se puede mencionar que los neoclásicos incurren continuamente en un grave problema conocido como 'falacia de composición' lo que pone en tela de juicios sus principales resultados. La falacia de composición se presenta de dos formas: i) cuando se introduce la figura del agente representativo y se supone que su conducta es generalizable a toda la economía, de donde viene la idea que la suma de las conductas individuales resulta en el resultado agregado, lo que desconoce como la incertidumbre hace que los individuos no tomen decisiones homogéneas bajo condiciones similares y además a través de la interacción en el mercado cambian sus decisiones por lo que la suma separada de las conductas no da el resultado agregado; y ii) cuando se abusa del ceteris paribus creyendo válido el resultado de un mercado ignorando sus efectos sobre otros. El ejemplo típico es cuando se supone que la reducción del salario mejora el empleo mirando el mercado de trabajo aisladamente sin tener en cuenta el impacto sobre el mercado de bienes y por ende los niveles de demanda (Neffa et. al., 2006).

\section{Conclusiones}

El presente artículo ha evidenciado una fragilidad epistemológica en la construcción de la teoría macroeconómica, dado que esta teoría ha tratado de seguir el molde de las ciencias duras de manera equivocada a través de un método científico riguroso pero tergiversado, pues confunde lo fines con los medios. En ese sentido, la cientificidad y el progreso de la macroeconomía como campo de estudio se han medido por el grado de consistencia lógica y matemática de los modelos (empirismo lógico), más que por su capacidad de explicación de los fenómenos que estudia. Así pues, la macroeconomía neoclásica que es percibida como un caso aplicado de la teoría general de la economía, la microeconomía, podría considerarse como la más científica de las ciencias sociales, pero contrario a ello, es percibida como un campo del conocimiento débil, inmaduro y desconectado de la realidad.

La unicidad en el camino que siguió la macroeconomía en su construcción teórica- científica se caracterizó por la selección de un conjunto de axiomas centrales (hard core), como fiel representación del mundo económico en su mayor estado de pureza fruto de la reflexión introspectiva. Esto sentó las bases de un sistema cerrado que permitió la consolidación matemática de los modelos teóricos haciéndolos más científicos, lo que finalmente derivó en leyes de comportamiento entre variables, que son útiles para la predicción.

Una de las falencias que presenta esta versión única de la construcción teórica (Euclidiana), es que la creación de conocimiento se da en una sola dirección, de la teoría hacia la realidad. Lo anterior niega la posibilidad de retroalimentación entre la teoría y la realidad, lo que al final termina en una total desconexión de la primera a la última con nefastas consecuencias en su aplicación práctica. 
La respuesta a este desafío por parte del mainstream fue asumir algunas imperfecciones de mercado que, sin cuestionar el hard core, relajan algunos de los axiomas principales del modelo acercando su explicación a la realidad, lo que se evidencia en modelos NMK con rigideces de precios o problemas de asimetría en la información para la NMC. No obstante, a pesar de que lo anterior pareciera una refinación de la capacidad de predicción del modelo, éste sigue sin desafiar los axiomas fundamentales, por lo que la realidad termina siendo una versión imperfecta de la expresión pura del mercado, lo cual termina influenciando las recomendaciones de política económica que buscan acercar la realidad al mundo.

Adicionalmente, el costo de no someter a cuestionamiento y comprobación empírica el hard core omite variables relevantes en la explicación de los fenómenos, que pueden cambiar completamente la lecturas de la realidad que hacen los modelos, y por supuesto, tener efectos perversos en su aplicación. Los cuestionamientos post keynesianos son evidencia de cómo la teoría cambia radicalmente si se ponen en duda los axiomas del mainstream o se introducen algunos otros.

Por ejemplo, cuestionar la noción de equilibrio automático del mainstream es poner en duda la capacidad de los precios para alcanzar el equilibrio a corto y largo plazo de los mercados, lo que ha constituido un pilar fundamental de este modo de pensar.

Para los post keynesianos no es la rigidez de precios la que evita ajuste, como cree la NMK, sino un estado de quietud en la demanda agregada por debajo del pleno empleo que se da por una satisfacción en las expectativas empresariales a ese nivel. Lo anterior, refleja que las decisiones óptimas de los individuos plenamente racionales se desvirtúan en un escenario de incertidumbre fundamental donde la regla es la no ergodicidad y el path dependence. Esto al final deriva en posiciones que reconocen en la demanda como un factor de restauración del pleno empleo y estímulo al crecimiento, contrario al mainstream donde el hard core se materializa en las hipótesis de neutralidad del dinero y equivalencia ricardiana que consideran neutro el empleo y nivel de actividad económica a corto y largo plazo ante variaciones de la política monetaria y fiscal del lado de la demanda.

Otra falencia sobre el método mainstream es que al establecerse como el único camino de construcción científica en macroeconomía, desconociendo otros modos de pensar como el post keynesiano, marxista y austriaco con sus propios métodos de investigación, elección de variables relevantes, relaciones de causalidad, etc., al negarse a la pluralidad el mainstream cierra a la macroeconomía a enriquecerse del debate, encontrar formas alternativas para abordar y solucionar las problemas, que otorgarían mayores grados de libertad a la política económica, y en general todos perderían, porque la teoría macroeconomía no avanza en el sentido Babilónico de Laudan y Feyeraben. Además, esto debería manifestarse en todas las esferas del mundo académico por medio de trasformaciones en el currículo, y en la no segregación en los medios de publicación y difusión del conocimiento, etc.

Finalmente, el ejemplo de la retroducción post keynesiana muestra otra forma de construir conocimiento que construye las preguntas de investigación, las variables relevantes y el grado de complejidad en el problema a partir de una revisión ontológica. Luego el proceso deductivo siempre se encuentra subordinado 
a la inspección ontológica inicial. Allí se puede evidenciar que la matemática se vuelve lo que es, una herramienta de representación de un problema y no la forma de validar si el conocimiento es científico. Lo mismo sucede con la comprobación empírica de la teoría macroeconómica que puede ser empleada desde cualquier perspectiva metodológica, lo que derivará en trasformación de variables, relaciones y causalidad distinta.

\section{Referencias}

ARESTIS, Philp; SAWYER, Malcom (2009), path Dependency and Macroeconomics, palgrave Macmillan. New York, $280 \mathrm{p}$.

ARROW, K; DEBREU, G (1954). Existence of an equilibrium for a competitive economy. En: Econometrica. Julio, Vol. 22, No. 003. Standford, Estados Unidos, pp. 265-290.

BERNAL, Cesar (2000). Metodología de la Investigación para Administración y Economía, Prentice Hall. Bogotá, $267 \mathrm{p}$.

BLAUG, Mark (1980). La metodología de la economía o cómo explican los economistas. Alianza Editorial. Madrid, $330 \mathrm{p}$.

BOUCHAOUD, Jean (2008). Economics needs a scientific revolution. En: Nature. Octubre, No. 455. Estados Unidos, pp. 1181.

CARABALLO, María Angeles; Galindo, Miguel Angel; Usabiaga, Carlos (2000). La relación entre la nueva economía keynesiana y la economía postkeynesiana: una interpretación. En: Boletín Económico. Julio, No. 2658. Madrid, España, pp. 13-21.

CENCINI, Alvaro (2005). Macroeconomic foundations of macroeconomics. Routledge. New York, 354 p.

CHICK, Victoria (1990). La macroeconomía según Keynes. Alianza Editorial. Madrid, 412 p.

CYNAMON, Barry; FAZZARI, Steven (2013). End of the Consumer Age En: After the great recession, de CYNAMON, Barry; Fazzari, Steven; Setterfield, Mark. Cambridge University Press. New York, pp. 129-157.

DAVIDSON, Paul (2011), post Keynesian macroeconomic theory. Edward Elwar. Northamton, 354 p.

DENIS, Andi, pluralism in economics education. En Teaching Post Keynesian Economics, de JESPERSEN, Jesper; OVE, Mongens. Edward Elgar. Northampton, pp. 88-105.

DOW, Sheila (1998). The Methodology of Macroeconomics Thought. Edward Elgar. Northampton, 255 p.

FRIEDMAN, Milton (1953). Essays in Positive Economics. The University of Chicago Press. Chicago, 329 p.

GONZÁLEZ, J. De la ciencia de la economía a la economía de la ciencia. En Ciencia Económica y Economía de la Ciencia reflexiones folosófico-metodológicas, de ÁVILA, Alfonso; GONZÁLEZ, Wenceslao; MARQUÉS, Gustavo. Fondo de Cultura Económica. Madrid, pp. 11-37. 
HEIJDRA, Beben; VAN DER PLOEG, Frederick (2009). Foundations of Modern macroeconomics. Oxford University Press. New York, 789 p.

HENRY, John (2003). Time in Economic Theory. En The Elgar Companion to Port Keynesian Economics, de King, J. Edward Elgar. Northampton, pp. 341-345.

JESPERSEN, Jesper (2009). Macroeconomic Methodology a Post Keynesian Perspective. Edward Elgar. Northampton, $247 \mathrm{p}$.

JONES, Charles (2009). Macroeconomía. Barcelona. Antoni Bosch, 675 p.

KALDOR, Nicholas (1972). The irrelevance of equilibrium economics. En: Economic Journal. Diciembre, vol.82, No.328. Reino Unido, pp. 1237-1255.

KEYNES, John (1936). La Teoría General de la Ocupación, el interés y el Dinero. Aosta. Madrid, 480 p.

KEYNES, John (1937). Teoría General del Empleo. En: The Quarterly Journal of Economics. Febrero, Vol. 51, No2. Reino Unido, pp. 209-223.

LAVOIE, Marc (1992). Foundations of Post Keynesian Economic Analysis. Edward Elgar. Vermont, 461 p.

LAVOIE, Marc (2006). Introduction to Post Keynesian Economics, palgrave. New York, 150 p.

LAWSON, Tony (2003). Reorienting economics. Routledge. London, 376 p.

LOPEZ, Julio. La Economía de Michal Kalecki y el capitalismo actual. Fondo de Cultura Económica. México D.F., 295 p.

LOPEZ, Julio; ASSOUS, Michael. Michal Kalecki, palgrave Macmillan. NewYork, 256p.Biografía de Michal Kalecki. Tomado de: http://www.goodreads.com/book/show/8739403-michal-kalecki.

MITCHELL, W; Muysken, J (2008). Full Employment Abandoned: shifting and policy failures. Edward Elgar. Northampton, 289 p.

MORATA, Enerique (2011). La Economía liberal es una Pseudociencia. En: Kaos en la red. Septiembre. (En línea) Disponible en: www.kaosenlared.net/noticias/bunge-economia.pseudociencia.

NEFFA, Julio; FÉLIZ, Mariano; PANIGO, Demian (2006). Teorias Económicas Sobre el Mercado de Trabajo: marxistas y keynesianos. Fondo de Cultura Económica. Buenos Aires, 188 p.

PALSSON SYLL, Lars (2012). Rational expectations - $A$ fallacious foundation for macroeconomics in a non ergodic world. En: Real World Economic Review. Diciembre, No. 62, pp. 34-50.

REINERT, Erik (2012). Neo-classical economics: A trail of economic destruction since the 1970's. En: Real World Economic Review. Junio, No. 60, pp. 2-17.

ROBBINS, Lionel (1932). Ensayo sobre la naturaleza y significación de la ciencia económica. Bussiness \& Economics. 41 p.

ROBINSON, Joan (1980). Time in Economic theory. En: Kiklos. Vol. 33, No. 2, pp. 219-229.

SCARANO, E (2001). La Economía Neoclásica como Ciencia. En Ciencia Económica y Economía de la Ciencia, de Avila, A.; González, W.; Maqués, G. 11-37. Fondo de Cultura Económica. Madrid, pp. 11-37.

SCHETTKAT, Ronald (2010). ¿Hara falta un terremoto para que despierte la teoría económica?. En: Revista Internacional del Trabajo. Septiembre, Vol. 129, No. 2. España, pp. 205-229.

SNOWDON, Brian; Vane, Howard; Winarczyk, Peter. Modern Macroeconomics. Edward Elgar. Northampton, $460 \mathrm{p}$.

SNOWDON, B.; Vane, H. Modern Macroeconomics. Edward Elgar. Northampton, segunda edición. 803 p.

YOUNG, Allyn. (1928). Increasing and economic progress. En: Economic Journal, Vol. 38, No. 52, Reino Unido, pp. 527-542. 